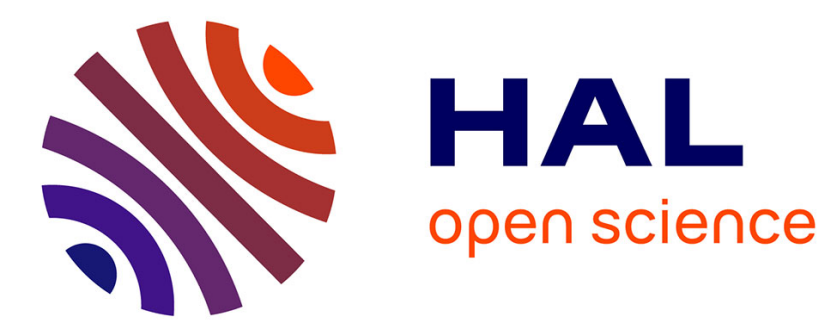

\title{
Citizen Engagement with Information Aggregation Markets
}

Efthimios Bothos, Dimitris Apostolou, Gregoris Mentzas

\section{To cite this version:}

Efthimios Bothos, Dimitris Apostolou, Gregoris Mentzas. Citizen Engagement with Information Aggregation Markets. 3rd Electronic Participation (ePart), Aug 2011, Delft, Netherlands. pp.274-285, 10.1007/978-3-642-23333-3_24. hal-01589382

\section{HAL Id: hal-01589382 \\ https://hal.inria.fr/hal-01589382}

Submitted on 18 Sep 2017

HAL is a multi-disciplinary open access archive for the deposit and dissemination of scientific research documents, whether they are published or not. The documents may come from teaching and research institutions in France or abroad, or from public or private research centers.
L'archive ouverte pluridisciplinaire HAL, est destinée au dépôt et à la diffusion de documents scientifiques de niveau recherche, publiés ou non, émanant des établissements d'enseignement et de recherche français ou étrangers, des laboratoires publics ou privés. 


\title{
Citizen Engagement with Information Aggregation Markets
}

\author{
Efthimios Bothos ${ }^{1}$, Dimitris Apostolou², Gregoris Mentzas ${ }^{1}$, \\ ${ }^{1}$ Institute of Communication and Computer Systems, National Technical University of \\ Athens, Iroon Polytechniou 9 Zografou Athens Greece 15780 \\ mpthim@mail.ntua.gr,gmentzas@mail.ntua.gr \\ ${ }^{2}$ University of Piraeus, Karaoli \& Dimitriou St. 80 Piraeus Greece 18534 \\ dapost@mail.ntua.gr
}

\begin{abstract}
Participatory governance entails converting citizens from passive users of administrative decisions into active participants of political procedures. Public institutions and organizations can benefit from methods and tools able to aggregate and interpret information dispersed among citizens. In this paper we explore the use of Information Aggregation Markets (IAMs) for citizen engagement. We identify the benefits of IAMs and explain how markets can be used to aggregate citizens' opinions and views on policy issues. Furthermore we report on two real life cases where we deployed IAMs to assist the decision making processes of public organizations. The positive feedback from participants and decision makers provides empirical evidence on the benefits of IAMs as a method for engaging citizens in public policy decision making.
\end{abstract}

Keywords: Information aggregation markets, public participation, citizen engagement.

\section{Introduction}

In social systems, information, beliefs and opinions are heterogeneous and dispersed among individuals. Public institutions and organizations can gain a considerable advantage by exploring methods and tools which are able to aggregate and interpret dispersed information. For instance, having precise knowledge of citizens' opinions and viewpoints can support public bodies in effective administration, while at the same time creating an enduring bond between citizens and administrators, based on active participation, trust and transparency.

Participatory governance entails converting citizens from passive users of administrative decisions into active participants of political procedures. In the recent few years there has been an observed trend toward increased involvement of the public in the affairs and decisions of policy-setting bodies [1]. To this end, a number of Internet technologies which allow users to interact, collaborate as well as express their beliefs and opinions can be utilized. These technologies, termed as Web 2.0 [2], provide wider applicability compared to traditional approaches since they can be used to address issues at different political levels (small, medium or large cities, regions or 
nations) and can significantly reduce the cost and time of monitoring and aggregating citizens' opinions and preferences.

In the "Web 2.0 era" of services and applications citizens collectively contribute to a Web presence and generate massive content behind their virtual collaboration [3]. An exemplar of this new paradigm is "collective intelligence". Kapetanios [4] introduces this paradigm as "human-computer systems in which machines enable the collection and harvesting of large amounts of human-generated knowledge, while enabling emergent knowledge, i.e. computation and inference over the collected information, leading to answers, discoveries, or other results that are not found in the human contributions". Typical examples of collective intelligence include collaborative filtering, folksonomies and Information Aggregation Markets (IAMs). IAMs are speculative markets, the purpose of which is to collect and aggregate information in the price of contracts representing different outcomes of future events [5]. Contract prices hinge on the probability of an event occurring or not. Individuals influence these prices by buying and selling contract shares based on their prediction of the outcome. IAMs are characterized by their relatively easy deployment and high potential in providing significant value to organizations by leveraging contributions from a broad community of contributors and aggregating information about issues that would otherwise be difficult to capture.

In this paper we propose IAMs as a method which can be used by public institutions and organizations for engaging citizens in public decision making. In section 2 we discuss the various levels of citizen engagement in the Web 2.0 era and explain what citizens contribute and why. Section 3 introduces IAMs whereas section 4 analyses how such markets can be used to support citizen participation. In Section 5 we present the results of two real life cases where we utilized IAMs to support the decision making processes of public organizations by allowing citizens to evaluate policy options as well as to propose new ones. The paper concludes in Section 6 with a summary of our observations and suggestions for further research.

\section{E-Participation and Citizen Engagement}

According to OECD [6] democratic political participation must offer the means to be informed, the mechanisms to allow citizens to take part in the decision-making and the ability to contribute and influence the policy agenda. OECD defines three levels of interaction according to the nature and direction of the relationship between public bodies and citizens: a) Information, which is a one-way relationship in which the government produces and delivers information for use by the citizens, b) Consultation, which refers to a two-way relationship with the government in which citizens provide their feedback and c) Active participation, referring to a partnership in which citizens actively engage in defining the process and content of policy making.

Based on the aforementioned scale of citizens' engagement Macintosh [7] provides three levels of engagement that characterize e-Participation initiatives: 
- e-Enabling citizens is concerned with how technology can be used to reach the wider audience by providing a range of methods to cater for the diverse technical and communicative skills of citizens.

- e-Engaging with citizens addresses the issue of consulting a wider audience to enable deeper contributions and support deliberative debate on policy issues.

- e-Empowering citizens is concerned with supporting active participation and facilitating citizens' ideas to influence the political agenda.

The role of citizens in public decision making becomes increasingly important in consultation (e-Engaging) and active participation (e-Empowering) initiatives as they can contribute in a variety of different ways, including exploring, validating and reconciling ideas [8]. With validating and evaluating ideas the public can support the decision-maker to check ideas with the on-the-ground perspective. With exploring ideas, the focus is on divergent input and conversations, whereby the public can bring ideas, suggestions, information and perspectives into the decision-making process. Another contribution that the public can provide relates to reconciliation of diverse ideas. These are more convergent discussions that emphasize trade-offs and the weighing of values. The aforementioned concepts are not mutually exclusive as one public involvement initiative might be designed to explore an issue and validate (options, while another might encompass all three types of input).

To interact with the public, one must somehow communicate with it. Recent innovations in the technologies of communication have affected the feasibility of various methods for public participation, leading to a renewed interest for engaging the public in decision making with the emergence of information technology applications for e-Participation. This is evident from the number of implementations around the globe such as Estonia's TOM portal (http://tom.riik.ee/) and Singapore's Government Consultation Portal (http://www.ura.gov.sg/econsult/index.htm). The impetus to implement e-Participation can also be attributed to the growing awareness of the need to attain more democratic governance [9]. OECD [6] has indicated that democratic governments are under pressure to adopt a new approach to policymaking, placing greater emphasis on citizen involvement both upstream and downstream to decision-making.

Regarding the question of why citizens participate in policy decision making, the review paper of Phang and Kankanhalli [10] lists five major theories: (1) the Socioeconomic Model of Participation, (2) the Rational Model of Participation, (3) the Civic Voluntarism Model, (4) the General Incentives Model and (5) the Social Capital Theory of Participation. The socio-economic model attempts to explain citizen participation in terms of the social circumstances of individuals, such as age, education level and financial status, which shape their attitude towards participating [11]. Individuals who are older, better educated and wealthier are more likely to participate than those who are not. The rational choice model of participation views citizen participation as a rational activity that serves to promote or defend the goals of participants with the maximum of benefits and the minimum of costs [12]. Citizens obtain benefits such as the ability to influence policy outcomes in ways that is to their advantage, while costs include effort and financial resources that one needs to incur to participate. 
The civic voluntarism model [13] explains participation by addressing the question of why people do not participate, and suggests three answers: because they can't due to lack of resources (e.g. money, time, and civic skills); they don't want due to lack motivation; and because nobody asked them to. The general incentives model [14] explains citizen participation by synthesizing social factors (e.g. norms) and individual factors (e.g. perceived costs and benefits). The social capital theory of participation attempts to explain citizen participation from a social network perspective. The main premise of the theory is that a community with stronger bonds between its members has a distinct advantage over a community with poor bonds [15].

Besides the aforementioned theories, IT features that affect citizens' participation are anonymity, simultaneity capability, connectivity and communality [10]. Research on group support systems has found a positive impact of anonymity on group performance (e.g. [16]) as anonymity may reduce unfavourable evaluation apprehension effects due to the social status of certain members. Evaluation apprehension is unwanted as it tends to inhibit participation in traditional face-to-face meetings [17] and by avoiding its occurrence, GSS are found to increase participation level of a group (see e.g. [18]). The simultaneity of IT is found to increase participation by overcoming production blocking that inhibits content generation process, as there is no need for one to wait for one's turn to express one's ideas [19]. It can also reduce the cognitive load and distraction of members in trying to remember their ideas while waiting for their turn.

Connectivity refers to the ability that enables individuals to directly communicate with each other, whereas communality refers to the availability of a commonly accessible pool of information to all ([20], [21]), ease individuals' participation in information sharing and exchanges. For example, Monge et al. [21] propose that increased provision of connectivity and communality would lead to an increased amount of information generated in the context of inter-organizational information systems.

Interventions on the non IT related factors that affect citizen participation cannot be easily controlled as they depend on characteristics of the society that require time in order to be enhanced such as educational status, financial status. On the other hand introducing methods and tools that encompass the IT features that positively influence citizen participation, such as Information Aggregation Markets, can be beneficial for public organization on shorter time-frames.

\section{Information Aggregation Markets}

Information Aggregation Markets (IAMs) are markets designed and run for the primary purpose of mining and aggregating information scattered among participants and subsequently using this information in the form of market values in order to make predictions about specific future events. IAMs are commonly known as 'prediction markets' because they are often used to predict future events. They are essentially "futures markets", i.e. forums for exchanging contracts whose payoffs are tied to unknown future events. The contracts in IAMs can be considered as a subset of the 
financial derivative called "future" and differ from those in traditional equity markets in that they are not typically tied to a claim of an ownership stake in a firm. Instead, the final price of these futures contracts depends on the outcome of a future event; upon market end, contracts' price incorporates the available information with respect to that event.

IAMs offer substantial benefits, including real time information aggregation as participants are incentivized immediately to submit new information, extraction of realistic expectations as traders 'put their money where their mouth is', high accuracy in predicting future events, as shown by previous papers cited later in section and increased scalability, due to their resemblance to financial markets.

In recent years, a significant increase has been documented in both the volume of academic literature on the subject [22], and enterprises putting the concept into actual use for information aggregation and decision support. In the corporate world, a number of companies including Hewlett Packard, Microsoft, Google, Siemens and Eli Lilly have experimented with IAMs to forecast sales, the success of new products or even estimate projects' completion time [23]. A number of information aggregation markets solutions for corporate applications are offered by specialized companies such as Inkling, Consensus Point in the US and Nosco and Pre:Kons in Europe whereas many sites on the Web (e.g. Intrade.com, Betfair.com, Nadex.com) offer information contracts in a number of areas including sports, politics, finance, law, entertainment, and even the weather. In addition, a recent study published at the European e-Participation portal suggests the use of information aggregation markets as a tool, which can leverage citizens' participation in European public policy [24].

Recent research has explored the use of IAMs for preferences' aggregation. In 'preference markets' participants engage in securities trading, the price of which represents the degree of preference for a decision option. Participants reveal their own preferences and their expectations of others' preferences, and converge towards an equilibrium that captures the consensus view [25]. This type of IAMs has been mainly applied in corporate settings for the selection of new ideas (see for example [26], [27]).

The public sector seems quite reluctant to introduce IAMs to improve public decision making, despite the benefits expected from the design of information markets for governance. In particular, Hanson [28] proposes IAMs as a new tool that 'will revolutionize governance' and Ledyard [29] and Hahn and Tetlock [30] describe a framework and identify the main characteristics an IAM should fulfil in order to perform well in situations relevant for policy decision making. In 2003, there was a controversial proposal to deploy information markets in order to predict terrorist events in the US and, based on the market outcome, to design appropriate policies relevant to national security. The so called Policy Analysis Market (PAM) was cancelled because the officials objected to the fact that terrorists could possibly affect the outcome while the government did not wish to disclose the kind of sensitive intelligence that an information market would reveal. 


\section{Information Aggregation Markets for Citizen Engagement}

The characteristics of IAMs are in line with IT features that affect participation. With IAMs, the private information and preferences of citizens are reflected in the price of contracts that represent policy options. Citizens buy contracts of policy options they prefer and sell those they do not approve. The target is citizens' motivation and their participation in the decision making process. As an example, suppose that a new policy addressing the problem of excessive $\mathrm{CO} 2$ emissions by automobiles is proposed. The IAMs e-Engaging approach would be to model the consequences of either adopting or not the proposed policy, by creating different contracts which reflect e.g. the impact on the percentage of $\mathrm{CO} 2$ emissions after 5 years.

IAMs can be configured to allow citizens propose alternative policy options raising the level of participation to e-Empowering. The new options are traded in the market together with the ones introduced by the policy makers. As a result the public, through the market, can indicate policies that experts have not considered yet. Table 1 summarizes who participates, what is being traded, how participants are involved and what the objective of IAMs in e-Empowering and e-Engaging is.

Table 1. Information Aggregation Markets for e-Participation.

\begin{tabular}{|c|c|c|}
\hline & e-Empowering & e-Engaging \\
\hline Who? & \multirow{2}{*}{\multicolumn{2}{|c|}{$\begin{array}{c}\text { Citizens } \\
\text { Identify the preferred and most promising policy options }\end{array}$}} \\
\hline Why? & & \\
\hline How? & $\begin{array}{l}\text { Participants express their preferences } \\
\text { by trading on decision options - they } \\
\text { can suggest alternatives }\end{array}$ & $\begin{array}{l}\text { Citizens predict the impact of } \\
\text { alternative policies or express } \\
\text { their preferences through trading }\end{array}$ \\
\hline Why? & $\begin{array}{ll}\text { - } & \text { Aggregate stakeholders’ } \\
\text { preferences } \\
\text { - } \quad \text { Identify new decision options }\end{array}$ & $\begin{array}{l}\text { - Prediction of policies’ impact } \\
\text { - } \begin{array}{l}\text { Aggregation of citizens’ } \\
\text { preferences }\end{array}\end{array}$ \\
\hline
\end{tabular}

When applying IAMs for citizen engagement, one should specifically consider liquidity, participants' incentives and the synthesis of participants groups. Liquidity, i.e. a significant number of transactions in the market, is needed to generate a reasonable price signal on the underlying value of a contract since transaction prices may not be representative of market participants' beliefs in markets with low number of transactions. In other terms, the outcome of an IAM can be used by decision makers only if prices do not provide biased measures of traders' beliefs. Nonetheless, theoretical analysis has shown that the practice to interpret IAM prices as probabilities that aggregate the information held by traders should be applied cautiously regardless of the liquidity problem. Manski [31] argues that in an all-ornothing IAM (i.e. markets populated with contracts that pay a fixed amount if a specified event occurs and nothing otherwise) populated with risk-neutral traders endowed with heterogeneous beliefs, the mean belief and the equilibrium price may differ substantially. Gjerstad [32] and Wolfers and Zitzewitz [33], however, show that the bias diminishes if traders have risk-averse utility function, and that the bias disappears if the coefficient of relative risk aversion is equal to one. These findings 
demonstrate that interpretation of prices in actual IAMs requires some knowledge of trader's risk preferences which is not always feasible.

With respect to incentives in IAMs, play money can be endowed to participants in order to avoid excess technical, regulatory, and fiduciary costs and redeem best performing participants with prizes as incentives. Past research showed that even play-money IAMs can be a dominant source of information ([34]).

Furthermore, in order for IAMs efficiently to aggregate information, they should attract a sound group of participants. Surowiecki [35] has provided a qualitative analysis of participant characteristics necessary for the market to be trustworthy: diversity of opinion, independence of thought and decentralization of knowledge. Wolfers and Zitchevitz [33] established a theoretical model and provided an account of sufficient conditions under which IAM prices aggregate private information held amongst participants. They concluded that, when participants are typically wellinformed, IAM prices will aggregate information into useful information. In the following sections we present two real-life use-cases of IAMs designed to assist public organizations in decision making.

\section{Real life cases of Information Aggregation Markets for Citizen Engagement}

The purpose of our pilots was to deploy IAMs in real settings in order to support the decision making processes of public institutions while allowing citizens to contribute by expressing their opinion. The first case was designed and executed at the State of Bremen in Germany in cooperation with the local ministry of education where citizens were asked to express their preferences on a set of policy options relevant to restructuring the bible history class at schools. In the second case we cooperated with the European Commission in the context of a public consultation held in order to acquire and evaluate future research directions regarding the use of information and communication technologies for enabling energy efficiency.

In both cases, the software IAMs were deployed on was IDeM [26]. The system can be utilized for aggregating participants' preferences for alternative policy options in market prices (relevant for e-Enabling initiatives) and with proper configuration it can allow traders to introduce new contracts in the market representing new policy options (relevant for e-Engaging initiatives).

To ensure adequate market liquidity even with low number of traders, IDeM implements a trading algorithm called continuous double auction with market maker (CDAwMM). When there are no matching offers the system acts as an 'always there' buyer and seller ready to accept buy and sell offers at a certain price. A logarithmic price function is used to determine the transaction cost [36].

Participants traded using play money; an initial amount 10.000 play money units was endowed to each trader upon registration together with an initial bundle of 50 contracts per policy option available in the market. Contracts could be traded at a price range of 0 to 100 since the price indicated the potential of success of the related policy option and were initially valued at 50 play money units in order to ensure a fair chance for all options. The duration of each market was fixed and announced at the 
home page of IDeM. A detailed tutorial explaining the basic principles of IAMs as well IDeM functionalities was included in the 'help section' of the software.

\subsection{Reforming the Bible History class at the State of Bremen}

In cooperation with the ministry of education of the German State of Bremen, we designed a real-life use of IAMs with the goal to evaluate policy options for refactoring the 'Bible history' class in Bremen schools. The officials at the State of Bremen wanted to modernize the class in order to address the needs of a multireligion society while involving citizens in the decision making process. The initiative was carried out in two phases. Initially a web-based forum was setup where the citizens of Bremen could submit ideas and views on the issue while engaging in an online discussion. The purpose of the forum was to gather citizens' views and remained open from 9/3/2009 to 20/3/2009. Next, the submitted views and comments were processed by the officials and a set of seven alternative options were derived.

We created a web-based IAM, registered the seven policy options together with their descriptions (as an example one of the policy options was: Title 'Separate classes for each religion', Description 'BGU is replaced by separate classes of Christian, Jewish and Islamic religious education, as well as philosophy / ethics. Skilled teachers with deep knowledge of the specific religion are responsible for each class') and posted a call for participation on the web-based forum. The multilingual capabilities of IDeM allowed us to use the German language in this case. Participants could not propose new policy options in the market and expressed their opinion by investing on the existing ones. The market remained active for 14 days, between 20/3/2009 and 3/4/2009. 42 users registered in our IAM of which 30 participated actively. The total number of transactions was 302; hence the average number of transactions per participant was 7.1. The maximum number of transactions per contract was 60 and the minimum 28.

The officials agreed that participation was satisfying. Two different questionnaires were prepared, one for the administrators and one for the traders. The former was completed by 3 administrators and the latter by 7 traders. Market administrators were satisfied by user participation and the results of the market. As quoted by one of the decision makers of the pilot in Bremen "Using Information Markets we experienced increased participation. Although we didn't take any specific measures to promote participation, people simply responded promptly".

Furthermore the ranking provided by the market, which was calculated using the weighted average price of the transactions, proved particularly useful and the officials at the ministry of education informed us that they were going to consider it when reaching their final decision.

Traders stated that they participated for the first time in an IAM. All but one agreed that they would be willing to take part in a similar market in the future. The trader who objected expressed the opinion that the capitalistic characteristics of the IAMs could lead to manipulation effects and speculative bubbles like those we are experience in the present economic crisis. Furthermore all traders expressed their concerns whether the outcome of the market would be considered by the officials as 
they felt that the decisions were directed by the central government and their opinion would not matter the most.

\subsection{European Commission Consultation on Information and Communication Technologies for Enabling Energy Efficiency}

The case was designed for a European Commission (EC) public consultation on Information and Communication Technologies for enabling energy efficiency. This endeavour was part of the interactive policy making initiative of the EC. The purpose of deploying IAMs in this context was to allow people from all over Europe to submit and evaluate future research directions relevant to the use of ICT for enabling energy efficiency, allowing them to express their opinions by proposing and trading idea contracts. Ideas placed in the market had the benefit of being scrutinized by a wide range of peers. In the invitation that was sent, participants were encouraged to especially consider and focus on the potential effects of user-driven open innovation in the area of Structural Change, i.e. ICT-enabled structural changes for a low-carbon society. The reason was that that enabling structural changes in Business/Work/Mobility models across the economy and society is the most challenging, least clear and yet potentially greatest area of opportunity.

An initial number of three ideas were used for the commencement of the market. Traders were able to enter new ideas in the 1 st week of the market operation. We asked participants to describe their ideas as clearly as possible but shortly. Once the appropriate information had been entered, the ideas automatically were inserted in the market. We agreed with the stakeholders that no more than 18 ideas should enter the market, so a 'first come first served' approach was enforced. The invitation was sent to approximately 2000 people from across Europe and 63 registered. Non-monetary and monetary incentives were provided to the idea creators and the market winner.

For the idea creators the incentive was that all proposed ideas were to be communicated to the EC officials thus increasing the likelihood of potential funding of the winning ideas. The market winner received a complementary registration for the international conference in a relevant area. The market operation started on 4/7/2008, remained open for approximately 3 weeks until 21/7/2008 and participants were able to trade 24/7. Traders were asked to perform as many transactions as possible, on the basis of what they thought the "winning ideas" could be and at the same time would maximize the valuation of their portfolio. As a minimum, traders were encouraged to visit the market once every day and revise their position accordingly. During the trading period 561 transactions occurred by 34 active members of the market (active members were considered the users that made more than 1 transaction in the market). We managed to attract a diverse group of participants from across Europe (10 difference European countries), with fairly wide age range (28 to over 57 years old), experience (1 to over 21 years of working experience) and professional background (including Engineering, Management and Marketing).

Upon market end participants were asked to fill an online questionnaire; we received a total of 14 completed questionnaires. An overwhelming majority of the respondents (85\%) indicated that they use information market as for the first time. 
$78 \%$ of them also stated that they would participate again in a similar market if they were requested. This percentage is quite important and shows the success the market had. It is noteworthy to mention that before participating in the market almost $72 \%$ of them did not believe that the concept of IM would be useful. However, after participating in a $78 \%$ of them support that they, now, believe that IAMs is a means to successfully evaluate policy options and also propose new options.

Furthermore semi-structured interviews were conducted with decision makers in order to gather feedback on the usefulness and the benefits of our approach and a positive feedback was received. An EU official stated "This endeavour proved very interesting and useful. We received many interesting, diverse and innovative ideas Overall, we were very satisfied with the quality of the contributions, although certain ideas were pretty 'wild' and cannot not be readily utilized". With respect to the submitted ideas, we reached our target to receive 18 ideas by participants fairly easily and all were submitted during the first two weeks of market operation.

\section{Conclusions}

In this paper we proposed Information Aggregation Markets as a promising method for citizen engagement in public decision making. We analysed the benefits of such markets for e-Engaging and e-Empowering initiatives and explained how markets can be designed and deployed by public institutions and organizations in order to allow citizens' involvement in the processes of selection and evaluation of new policies. Moreover we reported on two real life cases in which we applied IAMs in cooperation with public bodies. In both cases decision makers where pleased by the market output and appreciated the fact that they gained insight into participants' opinions. Furthermore they stated that they would consider the results before reaching a final decision. Users participated actively in the markets while admitting that IAMs can provide the means to successfully evaluate policy options and also propose new ones.

IAMs provide a sound solution to the incentive problems and can outperform alternative approaches to informing public administrations' decision-making. In addition they are scalable and can support an arbitrary number of participants whereas the output, i.e. the price signal, is simple enough to be directly taken into consideration. Nonetheless markets raise certain practical challenges; they are not suitable for all settings, and need to be designed and implemented carefully and sensitively to be effective. Markets may leak sensitive information in a way that other mechanisms do not (or do less), and this in turn can impact morale and motivation negatively, create legal complications by turning participants into "insiders". Markets may be subject to manipulation and it can be challenging to sustain participation.

However the practical performance of markets should not be compared to some absolute ideal, rather to the benefits or limitations of other alternatives [23]. Holding meetings, relying on 'expert' opinion, conducting surveys, or polling citizens are all information mechanisms with costs and potential weaknesses. Often these methods are not sufficiently appreciated and challenged. Our research provides evidence that IAMs can constitute a tool for public organizations in order to engage citizens in the decision making process and tap into citizens' knowledge and private information. 
Future research should focus on more systematic comparison of IAMs with alternative mechanisms in real world cases. For example, Graefe [37] compares the Delphi method of structured group deliberation with IAMs in a field experiment and concludes that markets perform as well as the Delphi method. On a more practical level, future integration of IAMs into well known social networks such as twitter and facebook could provide a much larger user base while overtaking the need for registration to new platform, not familiar to most citizens.

\section{References}

1. Rowe G. and Frewer L. J. (2005) 'A Typology of Public Engagement Mechanisms', Science Technology and Human Values, Vol. 30, No. 2, pp. 251-290.

2. O'reilly, T. (2007) 'What is Web 2.0: Design Patterns and Business Models for the Next Generation of Software', Communications \& Strategies, No. 65, pp. 17-37.

3. Lin, K. J. (2007) 'Building Web 2.0', IEEE Computer, Vol. 40, pp. 101-102.

4. Kapetanios, E. (2008) 'Quo Vadis computer science: From Turing to personal computer, personal content and collective intelligence’, Data \& Knowledge Engineering, Vol. 67, No. 2, pp. 286-292.

5. Spann, M. and Skiera, B. (2003) 'Internet-Based Virtual Stock Markets for Business Forecasting', Management Science, Vol. 49, pp. 1310-1326.

6. OECD (2001). Citizens as Partners: Information, consultation and public participation in policy-making: OECD.

7. Macintosh, A. (2004) 'Characterizing E-Participation in Policy-Making', In the Proceedings of the Thirty-Seventh Annual Hawaii International Conference on System Sciences (HICSS-37), Big Island, Hawaii.

8. Peters, J., and Abud, M. (2009) 'E-consultation: Enabling democracy between elections', IRPP Choices, Vol. 15, No. 1.

9. Coleman, S., \& Gøtze, J. (2002) 'Bowling together: Online public engagement in policy deliberation', Journal Information Polity, Vol. 7, No. 4.

10. Phang, C. W, and Kankanhalli, A. (2005) 'A Research Framework for Citizen Participation via eConsultation’, AMCIS 2005 Proceedings. Paper 145. http://aisel.aisnet. org/amcis2005/145.

11. Parry, G., Moyser, G., and Day, N. (1992) 'Political participation and democracy in Britain’, Cambridge University Press, New York. USA.

12. Green, D., \& Shapiro, I. (1994) 'Pathologies of rational choice theory', Yale University Press, New Haven.

13. Verba, S., Schlozman, K, and Brady, H. (1995) 'Voice and equality: Civic voluntarism in American politics’, Cambridge, Mass., Harvard University Press.

14. Seyd, P., and Whiteley, P. (1992) 'Labor's grass roots: The politics of party membership', Oxford, Clarendon Press.

15. Pattie, C., Syed, P. and Whiteley, P. (2002) 'Citizenship and civic engagement: attitudes and behavior', presented at the Political Studies Association Annual Conference, University of Aberdeen, UK.

16. DeSanctis, G., \& Gallupe, R. B. (1987) 'A foundation for the study of group decision support systems’, Management Science, Vol. 33, No. 5, pp. 586-609.

17. McLeod, P. L., \& Elston, S. E. (1995) 'Persuasive linguistic devices in computersupported group discussion', Proceedings of Twenty-Eighth Hawaii International Conference on System Sciences, Los Alamitos, CA: IEEE Computer Society Press, pp. 20-31. 
18. Connolly, T., Jessup, L. M., \& Valacich, J. S. (1990) 'Effects of Anonymity and Evaluative Tone on Idea Generation in Computer-Mediated Groups'. Management Science, Vol. 36, No. 6, pp. 689-703.

19. Shepherd, M. M., Briggs, R. O., Reinig, B. A. Yen, J., \& Nunamaker, J. F. (1995) 'Invoking social comparison to improve electronic brainstorming: Beyond anonymity', Journal of Management Information Systems, Vol. 12, No. 3, pp. 155-170.

20. Fulk, J., Flanagin, A. J., Kalman, M. E., Monge, P. R., \& Ryan, T. (1996) 'Connective and communal public goods in interactive communication systems', Communication Theory, Vol. 6, No. 1, pp. 60-87.

21. Monge, P., Fulk, J., Kalman, M., Flanagin, A., Parnassa, C., and Rumsey, S. (1998) 'Production of collective action in alliance-based interorganizational communication and information systems', Organization Science, Vol. 9, No. 3, pp. 411-433.

22. Tziralis G. and Tatsiopoulos I. (2007) 'Prediction Markets: An Extended Literature Review', The Journal of Prediction Markets, Vol. 1, pp. 75-91.

23. Cherry S. (2007). 'Bet on it! Can a stock market of ideas help companies predict the future?', IEEE Spectrum, Vol. 44, pp. 48-53.

24. Millard J., Nielsen M. M., Warren R., Smith S., Macintosh A., Tarabanis K., Tambouris E., Panopoulou E., Efpraxia D., Parisopoulos K. (2009) 'European eParticipation Summary Report'.

25. Dahan, E., Soukhoroukova A. and Spann M. (2007) 'Preference markets: Organizing securities markets for opinions surveys with infinite scalability', Journal of Product Innovation Management, Vol. 27, No 7, pp. 937-954.

26. LaComb C. A., Barnett J. A., and Pan Q., (2007) 'The imagination market. Information' Systems Frontiers, Vol. 9, pp. 245-256.

27. Bothos, E., Apostolou, D., Mentzas, G. (2009) 'Collective intelligence for idea management with Internet-based information aggregation markets', Internet Research, Vol. 19, No. 1, pp. 26-41.

28. Hanson R. (2006) 'Decision Markets for Policy Advice', in E. Patashnik and A. Gerber (eds) Promoting the General Welfare: American Democracy and the Political Economy of Government Performance (Washington D.C., Brookings Institution Press).

29. Ledyard J. (2006) 'Design of information markets for policy analysis', in Information Markets: a New Way of Making Decisions, Hahn and Tecklock editors, The American Enterprise Institute Press.

30. Hahn R. W. and Tetlock P. C. (2005) 'Using information markets to improve public decision making’. Harvard Journal of Law and Public Policy, Vol. 29, pp. 213-289.

31. Manski, C. (2006) 'Interpreting the Predictions of Prediction Markets', Economic Letters, Vol. 91, No. 3, pp. 425-429.

32. Gjerstad, S. (2005) 'Risk Aversion, Beliefs, and Prediction Market Equilibrium', mimeo University of Arizona.

33. Wolfers J. and Zitzewitz E. (2004) 'Prediction markets', Journal of Economic Perspectives, Vol. 18, No. 2, pp. 107-126.

34. Servan-Schreiber, E., Wolfers, J., Pennock, D. and Galebach, B. (2004) 'Prediction Markets: Does Money Matter?’, Electronic Markets - The International Journal, Vol. 14, No. 3, pp. 243-251.

35. Surowiecki J. (2004) 'The Wisdom of Crowds', New York: Random House.

36. Hanson R. D. (2007) 'Logarithmic market scoring rules for modular combinatorial information aggregation', Journal of Prediction Markets, Vol. 1, No. 1, pp. 3-15.

37. Graefe, A. (2008) 'Group Decision Making - Meetings, Nominal Groups, Delphi, and Prediction Markets Compared’. Third Workshop on Prediction Markets, Chicago, USA. 